\title{
Runaway Energy Meters due to Conducted Electromagnetic Interference
}

\author{
Frank Leferink ${ }^{1,2}$, Cees Keyer ${ }^{3}$, Anton Melentjev ${ }^{3}$ \\ ${ }^{1}$ Thales Netherlands \\ Hengelo, The Netherlands \\ frank.leferink@nl.thalesgroup.com \\ ${ }^{2}$ University of Twente \\ Enschede, The Netherlands \\ frank.leferink@utwente.nl \\ ${ }^{3}$ University of Applied \\ Sciences Amsterdam, The \\ Netherlands
}

\begin{abstract}
More often consumers are complaining about the energy bill after the conventional electromechanical meter has been replaced by an electronic, or static, energy meter. Active infeed converters for photo-voltaic systems are a known source for interference to static meters. To investigate the root cause experiments on static meters have been performed in a controlled lab environment. Three-phase meters showed large deviations of more than $250 \%$ and $-\mathbf{4 6 \%}$. After dismantling it was revealed that the meters with the positive deviation used a Rogowski coil current sensor. The meter with a Hall effect-based current sensor gave the $-\mathbf{4 6} \%$ deviation.
\end{abstract}

Keywords: Static Meter, Electronic Meter, Conducted Interference

\section{INTRODUCTION}

The Ferraris principle meters, or electromechanical energy meters with moving parts, are being replaced by electronic, or static, energy meters. By adding a communication link these static meters are also capable of transmitting measured data. Some consumers are complaining about their energy bills after replacement of the energy meter, because the registered energy is higher with the static meter compared to the old Ferraris meter. The utility companies use the argument that the old meters were incorrect because of mechanical wear and consumers should be happy because they have been undercharged for many years. Energy generated by Photo-Voltaic (PV) installations is fed into the power grid using Active Infeed Converters (AIC). The lack of proper Electromagnetic Interference (EMI) standards, especially in the range $2-150 \mathrm{kHz}$, created possibilities to generate high interference levels, causing EMI [1]. As an example, two neighbouring farmers using the same PV system observed that on sunny days one PV generated only $40 \%$ of the energy generated by the other. After some experiments it was found that the power drive systems for the fans in the barn generated high conducted interference on the power lines, shown in Figure 1 and Figure 2, and as a result, the static energy meter failed to register the actual value [2]. Similar effects were observed during experiments with PV installations in Germany, and high interference levels generated by AICs caused faulty readings of the static energy meters [3], [4], [5]. This observation resulted in faster publication of the TR50579 [6] technical report and IEC 61000-4-19 standard [7]. To investigate the possible cause of EMI influencing the static energy meter reading, measurements were performed in a controlled laboratory environment on 1- and 3- phase meters.

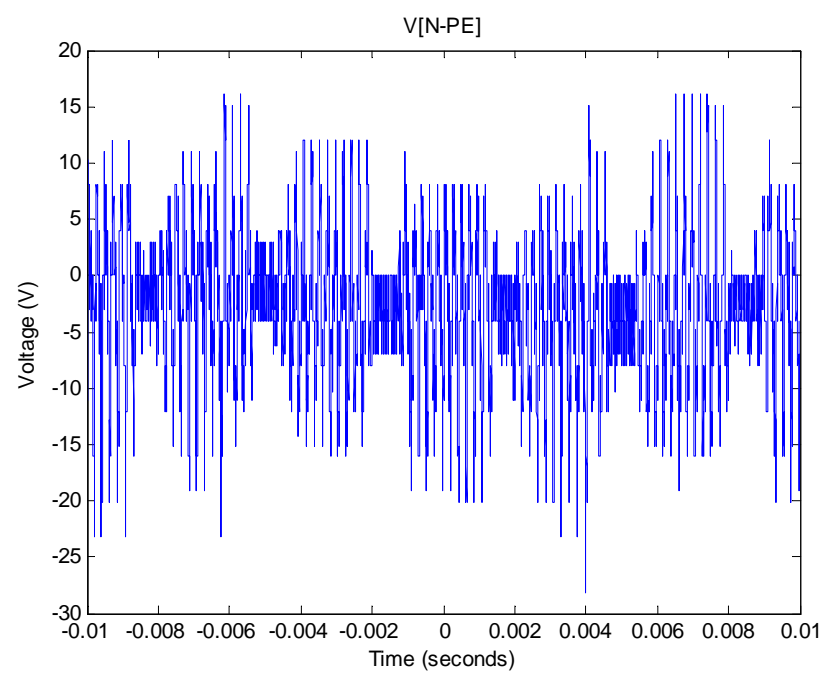

Fig.1: Neutral-earth voltage

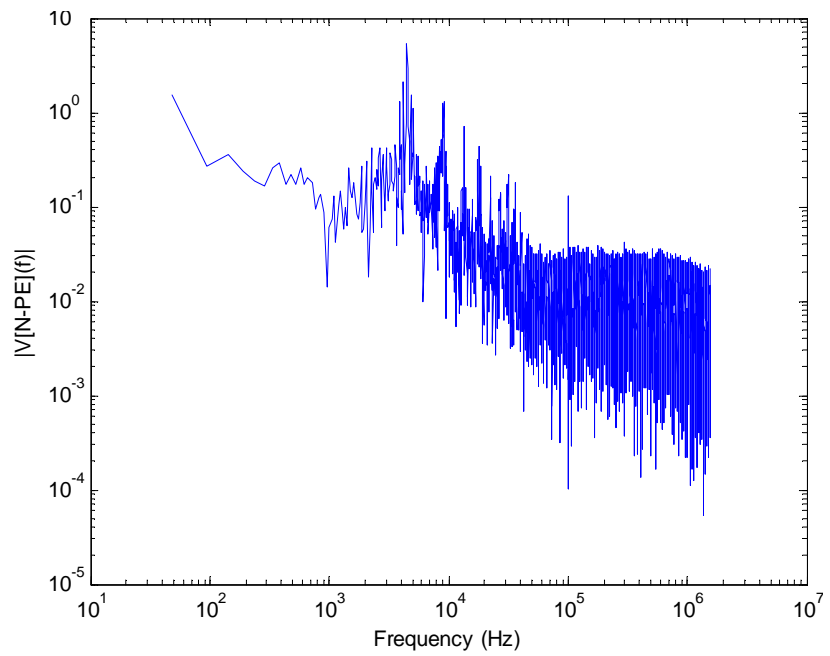

Fig.2: Amplitude spectrum of neutral-earth voltage 


\section{SINGLE-PHASE ENERGY METERS}

Single-phase static energy meters were measured using a fourquadrant amplifier from Spitzenberger \& Spies (S\&S) PAS 5000. This equipment can perform EMI measurements according several standards such as the IEC 61000-4-11 [8]. Measurements with ideal sinusoidal, and with distorted voltage waveform have been performed. Furthermore, interfering signals were injected using the CS101 test setup of MIL-STD $461 \mathrm{E}$ [9]. The frequency range was $30 \mathrm{~Hz}$ up to $150 \mathrm{kHz}$, and levels were around $10 \mathrm{Vpp}$. This setup replicates the IEC 61000-4-19 [7] test. The loads used during the tests were power resistors, strings of CFL and LED lamps, a power drive system, and a dimmer driving these lamps. A Dranetz PowerXplorer PX5-400, and an oscilloscope were used for reference energy measurements. The results can be summarized in one sentence: no deviation beyond the specification could be observed; no influence of interference due to interfering or distorted voltage, and no influence caused by interfering currents were observed.

\section{THREE-PHASE ENERGY METERS}

Four different three-phase static energy meters have been tested in series with an electromechanical meter. The accuracy class of the static meters is defined by the IEC 62053.21-22 standard [10] and are either class 1 or class 2 . The meters used in all tests were rated at 80, 85, 100, $120 \mathrm{~A}$, except for the electromechanical Ferraris meter which was rated at $30 \mathrm{~A}$ for $I_{\max }$. The three-phase meters were used in a three-phase test setup using normal mains supply, and in a single-phase test setup using the programmable power source with the fourquadrant amplifier from Spitzenberger \& Spies (S\&S) PAS 5000. The S\&S SyCore generator and the PAS 5000 are used to generate a controlled distortion-free ideal sinusoidal voltage waveform. The internal impedance of this source is less that $0.4+\mathrm{j} 0.25 \Omega$, as defined in the standard [8]. The test setup is drawn in Figure 3.

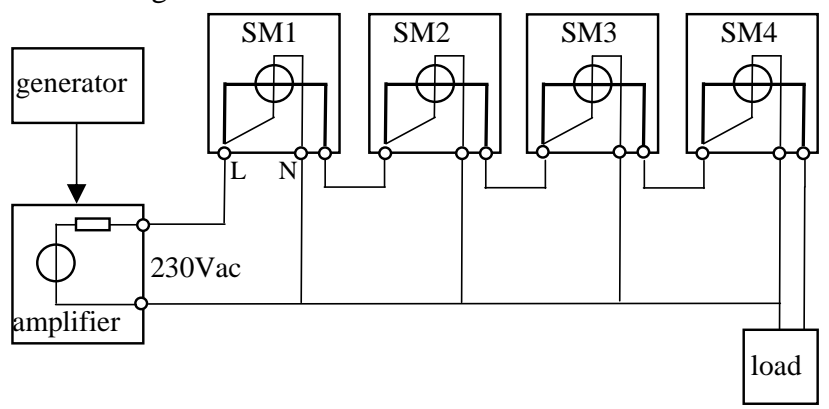

Fig. 3: Test setup

A resistive load, a string of CFL lamps and a string of LED lamps were used. These loads were controlled by a dimmer creating a chopped part of a sinusoidal waveform, in case a resistive load would be used. The waveforms for a dimmer at $45^{\circ}$ when using the electric heater and 30 CFL and 20 LED is shown in Figure 4.
The voltage dips in the voltage waveform are caused by the internal impedance of the four-quadrant amplifier, which is less than $0.4+\mathrm{j} 0.25 \Omega$. Tests were performed during at least 24 hours, and sometimes over the weekend, over a 48 hour period. The registered energy of the static meters was measured using an Arduino microprocessor and optical sensors for detecting the pulses from the LED on the static meter fronts. The readings were verified using the liquid crystal display (LCD) reading on the meter. A recently calibrated conventional electromechanical meter based on the Ferraris principle was used as reference, because consumers are also using this as reference. Most experiments have been repeated to confirm the conclusions, and repeated again, and again, because some of the static energy meters gave large differences. In Figure 5 the deviation with respect to the Ferraris meter is shown, using

$$
\text { Deviation [\%] }=\frac{E_{S M}-E_{\text {ferraris }}}{E_{\text {ferraris }}} 100 \%
$$

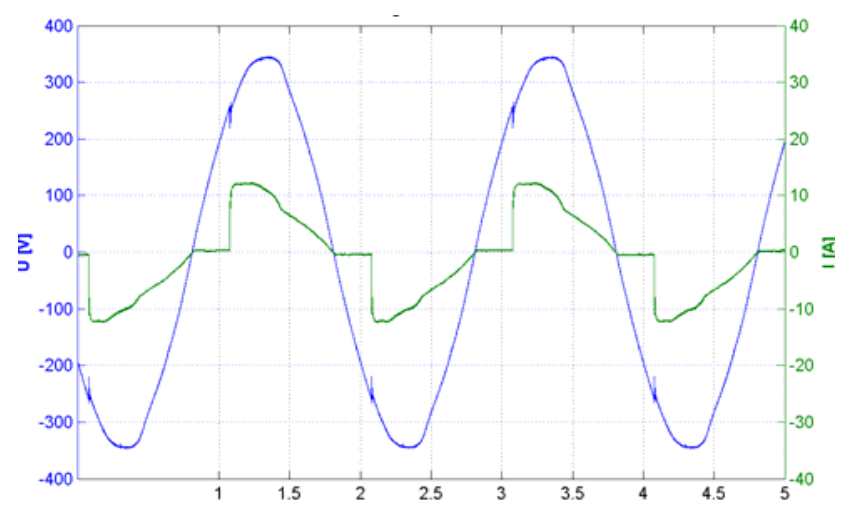

Fig.4: Voltage and current, for heater, CFL and LED as load, dimmer at $45^{\circ}$

These measurements have been performed using an standard non-distorted voltage generated by the four-quadrant amplifier with a defined low-impedance internal impedance. The observed effects are due to the pulsed currents consumed by the loads.

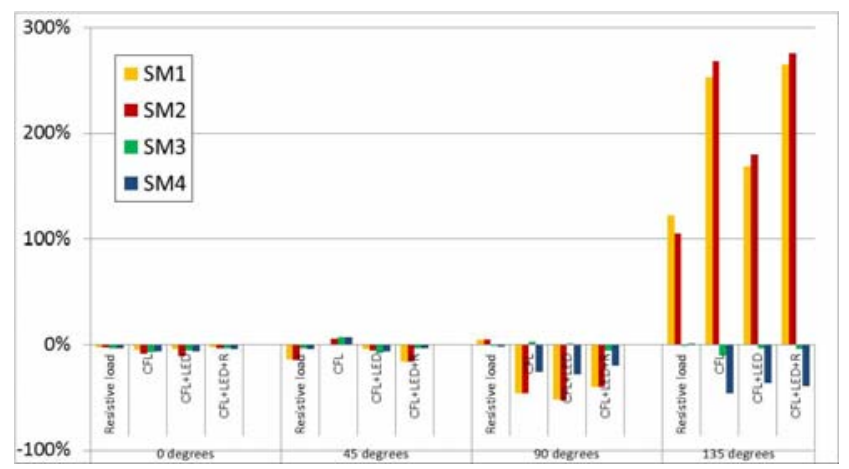

Fig.5: Deviation of static meter (SM) 1 to 4, referenced to an electromechanical (Ferraris) energy meter 


\section{INTERFERENCE ANALYSIS}

Four types of current sensors are widely used in static meters: the shunt resistor, current transformer, Hall effect-based current sensor, and Rogowski coil. Static Meter 1 (SM1) and SM2 are from the same manufacturer. SM1 was produced in 2013 and SM2 in 2007. After opening it was revealed that both are using the Rogowski principle. SM3, from 2007, used a current transformer, and SM4, 2014, the Hall sensor. The current transformer is the most expensive technique, and SM3 is the most costly meter, it results in the best reading, very similar to the reading of the electromechanical meter. The meter with the Hall sensor, SM4, is the best for the consumer because it resulted often in a negative reading, with a maximum of $-46 \%$. Readings taken by Rogowski coil meters are dramatically higher, at $+265 \%$ for SM1 and $+276 \%$ for SM2. The effect was consistent over the three phases, as is shown in Figure 6. Tests were repeated several times and the results were very repeatable, within a few percent.

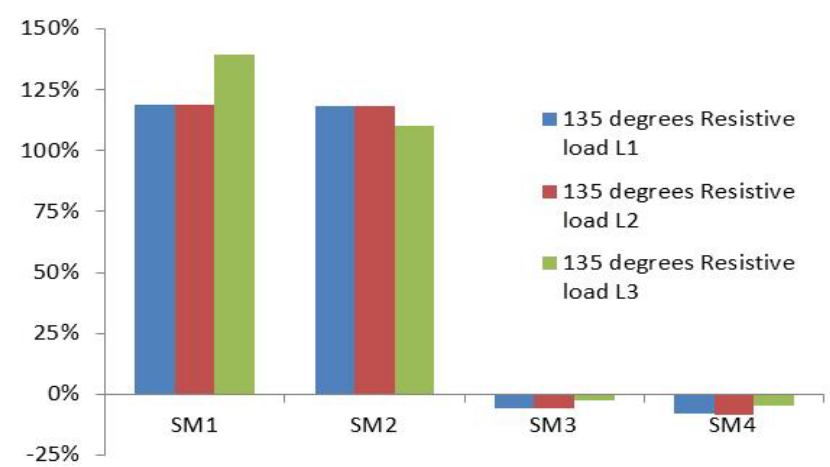

Fig. 6: Deviation of static meter (SM) 1 to 4, with resistive load (heater) and dimmer at $135^{\circ}$, for all three phases

Measurements were also performed using the mains supply and a balanced load over the three phases, but with the dimmer circuit in only one single phase. The deviations were consistent, but only a factor 3 lower because of the balanced loading.

\section{DISCUSSION}

Many experiments were performed to find out if static energy meters can provide inaccurate readings. Based on our own experience [2] the large conducted interference caused by power drive systems or some active infeed converters, as well as the high power line telecommunication (PLT) levels, were assumed to be a potential culprit. This interference can be solved by reducing the emission level of the interference sources, often simply by replacing the power drive system [2] or the AIC [11]. Large harmonic distortion of the mains supply could be another source of misreading, but, although observed for low-cost energy monitors, this could not be confirmed for the static energy meters.

The reason for faulty readings appears to be the current sensor, and the associated circuitry. As a Rogowski coil results in a time-derivative of the measured current, the measured voltage has to be integrated. Probably active integration is used instead of passive integration, and the input electronics are pushed in saturation caused by the high rise-time of the current. Although the peak current level is below the maximum level stated for the meters. As stated before, no information nor documentation at all is available from meter manufacturers.

The recently introduced standards [6], [7] only assume a damped sinewave current and voltage as potential interference. These signals are actually the pulse response of a larger system formed by the cabling. The experimental results presented in this paper show that static energy meters can be pushed into faulty reading (positive and negative) if sufficiently fast pulsed currents are drawn by the consumer. The actual response (damped sinewave) is not of interest anymore.

The observations of a consumer that were reported on an internet forum are consistent with the results contained in this paper: a small electronic circuit consumed only a very small amount of peak current, but caused the meter to read $500 \mathrm{~W}$, resulting in a yearly additional energy 'consumption' of 4380 kWh [12].

\section{CONCLUSION}

Reports of misreading of static, or electronic, energy meters due to conducted electromagnetic interference have been investigated. In one actual case the cause of misreading is the interfering currents caused by active infeed converters for renewable energy. Controlled experiments performed on static energy meters confirm that they can present still faulty readings and the main cause of interference appears to be the current sensor. Meters with a Rogowski coil current sensor showed a positive deviation of $276 \%$, compared to the reading of a conventional electromechanical meter based on the Ferraris principle. Meters with a Hall sensor showed a deviation of registered energy of $-46 \%$.

\section{REFERENCES}

[1] Frank Leferink, ''Conducted interference, challenges and interference cases’, IEEE Electromagnetic Compatibility Magazine, Volume 4, Quarter 1, 2015, pp. $78-85$

[2] R.B. Timens, 'Electromagnetic interference of equipment in power supply networks', $\mathrm{PhD}$ thesis University of Twente, 2013, ISBN 97890-365-0719-6

[3] Jörg Kirchhof, G. Klein, ' EMV - Grenzwertlücke - Wechselrichter stört Zähler“, 24. Symposium Photovoltaische Solarenergie, Bad Staffelstein, 2009

[4] Jörg Kirchhof, '’Grenzwertlücke - wechselrichter stört elektrizitätszähler', EMV 2010, Düsseldorf

[5] CLC/TR 50627 Study Report on Electromagnetic Interference between Electrical Equipment/Systems in the Frequency Range Below $150 \mathrm{kHz}$ Ed. 2, 2014

[6] CLC/TR50579, Electricity metering equipment - Severity levels, immunity requirements and test methods for conducted disturbances in the frequency range $2-150 \mathrm{kHz}, 2012$

[7] IEC 61000-4-19: Electromagnetic Compatibility (EMC) - Part 4-19: Testing and measurement techniques - Test for immunity to conducted, 
differential mode disturbances and signalling in the frequency range from $2 \mathrm{kHz}$ to $150 \mathrm{kHz}$, at a.c. power port, 2014

[8] IEC 61000-4-11:2004, Electromagnetic compatibility (EMC) - Part 4-11: Testing and measurement techniques- Voltage dips, short interruptions and voltage variations immunity tests

[9] MIL-STD 461E, Requirements for the control of electromagnetic interference characteristics of subsystems and equipment, 20 August 1999
[10] IEC 62053-21:2003 - Electricity metering equipment (a.c.) - particular requirements - part 21: Static meters for active energy (classes 1 and 2), 2003.

[11] http://www.1miljoenzonnepanelen.nl/contact/forum/nieuwepost/subject/slimme-meter-op-hol-geslagen-door-zonnepanelen

[12] https://forum.www.trosradar.nl/viewtopic.php?t=142703 